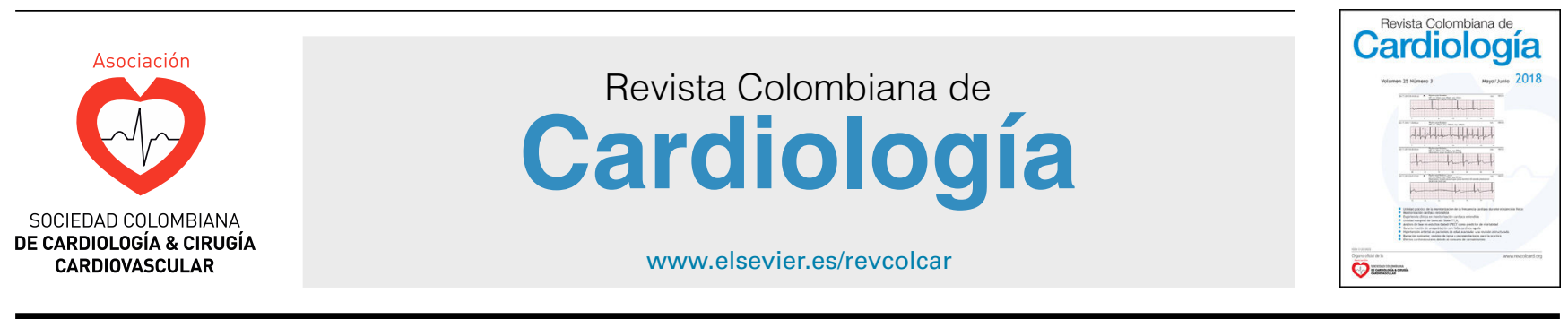

\title{
EDITORIAL
}

\section{Ethics in medical relationships with the pharmaceutical industry}

\author{
Diana P. Martínez
}

Grupo de Trabajo de Bioética Clínica, Sociedad Colombiana de Cardiología y Cirugía Cardiovascular. Bogotá Colombia

Utopia: "the dream of a few which becomes the nightmare of the others",

Fernando Savater

It is undeniable that the relationship of medical professionals with the pharmaceutical industry, just like all human activity, is subject to tensions which, depending on their development, may lead to a considerable number of ethical dilemmas in medical practice. ${ }^{1}$

An ethical dilemma is understood to be a moral situation, that is, one that posits how to act well, avoiding doing harm, evaluating the consequences of the act and obtaining the greatest benefit for most of the people involved, based on established rules "for the good". 2,3

A discussion of the existing ethical aspects of medical professionals'relationships with the pharmaceutical industry is a long road, mixing aspects of professional training, human nature, the health systems of the different countries in which medicine is practiced and the development of the global economy, as well as the development of the various business units and projects of multinational pharmaceutical companies, among others. ${ }^{2}$

It must be accepted that, in previous decades, medical professionalsćontinuing education was subject, to a large extent, to the pharmaceutical industry's sponsorship, and part of this industry's budget was dedicated to medical education, but also to the sometimes inordinate "support"

Véase contenido relacionado en DOI:

https: //doi.org/10.1016/j.rccar.2019.04.001

Correo electrónico: dimartru@gmail.com of these individuals. However, these sponsorships are now increasingly subject to the current development of strict spending policies within the various pharmaceutical industry companies. Some are more aware than others that, in previous years, the pharmaceutical industry's spending went above and beyond to excessive offers and benefits outside of what was strictly related to continuing education, leading to tacit preferential prescription contracts, among other things. As a result, today, a balanced and transparent relationship between medical professionals and the pharmaceutical industry is undoubtedly the greatest challenge facing medical scientific societies, the political health systems and the spending policies of the pharmaceutical industry. Thus, ethical training becomes the driving force for the development of responsible attitudes and guidelines, both for medical professionals as well as the pharmaceutical industry, inviting them to respect the autonomy of medical decisions and choices based on academic knowledge and in accord with the health policies and guidelines of their professional practice environment. ${ }^{3-5}$

I would now like to quote the words of Rogelio Altisent (Chair of Professionalism and Clinical Ethics at the Universidad de Zaragoza, president of the Comisión Central de Deontología de la Organización Médica Colegial de España [Central Deontological Commission of the Collegiate Medical Organization of Spain] from 2006 to 2009, and president of the Comité de Bioética de Aragón [Aragón Bioethics Committee] since 2013): "Continuing Professional Development is a process which should accompany the successive stages of a professional's life, throughout his/her times of motivation and crisis, and its ethical foundation should be understood, 
reflecting on the quality of care. Professionals who care for patients also need care to diagnose and overcome inertia, lack of initiative, skepticism, and lack of self-criticism. The quality of patient care can only be guaranteed if professionals have a satisfactory career progress, which requires that the personnel and human resources departments of healthcare institutions devote their best energies to caring for the advancement of their professionals. " 6

In other words, it is continuing medical education which can give medical professionals the tools needed for beginning and maintaining a proper relationship with the pharmaceutical industry. This process aims to strengthen the inherent and undeniable limitations of being human beings, which include rationality, self-interest and the innate pursuit of opportunities, all joined to the currently innumerable limitations of the political healthcare systems which foster a lack of motivation in professionals and leave continuing medical education, research programs and new healthcare policy development out of their budget, creating a large gap between medical practice and health policies. ${ }^{4,7-9}$

Historically, this gap has led to large voids in the motivation and training of medical professionals. Over time, it has allowed these professionals to be "used" by the pharmaceutical industry to discretely, and not so discretely, intercept their autonomy, inducing and diverting the prescription of medications and medical devices, among others, due to the conflict of interests created by the acquired "debts" of attentions, gifts and favors received through medical training sponsorships. ${ }^{1,5,9}$

Likewise, the different research protocols may expose medical scientific societies to equally concerning situations in the publication of results which are beneficial to the sponsoring industry and the omission or undervaluing of adverse events. This is combined with a lack of attention to respect for patient autonomy, with a frequently overestimated informed consent, and a lack of respect for the fair distribution of healthcare resources. The flattering results may determine the prescription of innovative pharamaceutical industry products and in this way increase the "perception" of therapeutic and biotechnological healthcare needs. 9,10

Today, it is clearly known that the development of new pharmaceutical and medical technology products does not grow linearly with healthcare budgets and policies which would allow for their application and payment. Therefore, routine medical practice has an ever increasing conflict in light of the lack of financial resources (even in countries with stable economies) to acquire all the innovative technologies presented by the pharmaceutical industry, which, it should be remembered, is one of the largest financial industries in the world. 8,11

Professionals are constantly faced with these different situations, and the marketing policies of the powerful pharmaceutical industry appear in the midst of their difficulties and limitations to offer a tempting and dangerous relief to their needs. In this situation, the pharmaceutical industry is also posed with a big dilemma between its social reason for being (that is, to contribute to discovery and innovation which will improve the prevention, treatment and rehabilitation of disease and thus the quality of life of different populations) and a need to generate profits, due to its commercial nature, which conflicts with its objectivity. ${ }^{9,10}$
This is why the invitation to a balanced and transparent relationship between medical professionals and the pharmaceutical industry makes all these limitations evident, so that in being aware of them, with critical thinking and arguments on both sides, they may be recognized and faced professionally and ethically, maintaining respect for the dignity of the endeavor of the medical profession as well as compliance with international health policies and the economic growth of the pharmaceutical industry. ${ }^{9}$

The ethical basis of medical practice is expressed under the principles of autonomy, that is to say, each individuals right to actively participate in the decisions made regarding his/her health and illness process, and the respect that should be given to this participation; the principle of beneficence, which seeks the patientś wellbeing in a timely fashion, analyzing the risk/benefit ratio of the different medical interventions; the principle of non-maleficence, which reminds medical professionals to do no harm; and, finally, the principle of justice in the distribution of resources, which refers to the value of equality and the rational use of healthcare resources. ${ }^{12}$

Similarly, medical practice should distance itself from scenarios that show disproportionate incentives and inappropriate requests which put the autonomy of medical care and the patientswellbeing at risk. Likewise, although at times it may be difficult, the medical community must be alert to disguised "marketing strategies" which induce the prescription of certain products, directly intercepting medical judgement and profesional integrity. ${ }^{1,9}$

Every day brings a new challenge in the relationship of medical professionals with the pharmaceutical industry, because every day there are many decisions to be made, behind each of which there is risk for the patient, for the autonomy of medical practice, for the responsible management of the financial benefits derived from medical practice and for the financial objectives of the industry and the political health systems. This demands that, every day, medical professionals and the pharmaceutical industry focus their attention on these topics and especially those related to continuing medical education and research development. ${ }^{12}$

Given that, in current medical practice, healthcare efficiency and productivity policies do not include opportunities for continuing medical education, and given its ever increasing cost, universities and healthcare institutions have a great responsibility to provide neutral environments for critical academic training and to form research groups that take ownership in generating new knowledge which will supply the needs of the local medical community and the society it serves, in a timely fashion. In addition, they should access political spaces which will allow them to actively intervene in the different health policies which have neglected the continuing education of healthcare professionals, leading to a great lack of motivation and high inertia in medical practice. Likewise, universities and healthcare institutions, when receiving sponsorship from the pharmaceutical industry to carry out academic events, should have clear, previously established limits with regard to the industryś participation in academic topics. Thus, the pharmaceutical industry should increasingly implement clear and transparent policies for the adequate use of its resources in research and continuing medical education sponsorships. 6,9,11-13 They should also gain political spaces which will allow 
them to actively intervene in the various health policies which have neglected the continuing education of healthcare professionals, leading to a lack of motivation and inertia in medical practice.

On the other hand, if medical professionals, individually, want to preserve their autonomy and professional independence, they should keep their distance from agreements with the pharmaceutical industry that would cause them concern if they were to become known by the medical community, in general. These professionals should stay away from direct payments, either in cash or in kind, from the pharmaceutical industry, tied to a given prescription for a product or device, or to "pseudo" scientific events. 6,9

Lastly, although the relationship between the pharmaceutical industry and medical professionals has been historical and although immoral practices with regard to medical practice and the preferential prescription of some products have been engaged in for years, in the name of marketing strategies, these practices should not be accepted just because they are common. The development of comprehensive medical training should lead the entire professional community to defend and uphold their autonomy and professional dignity.

\section{Bibliografía}

1. Brody $\mathrm{H}$. Clarifying conflict of interest. Am J Bioethics. 2011;11:23-8.

2. Keller F, Marczewski K, Pavlović D. The relationship between the physician and pharmaceutical industry: background ethics and regulation proposals. Croat Med J. 2016;57:398-401, http://dx.doi.org/10.3325/cmj.2016.57.398.
3. DeJong C, Dudley A. Reconsidering physician pharmaceutical industry relationships. JAMA. 2017;317, 1772/3.

4. Suresh M, Kamala R. Championing ethics. Industry Viewpoint. 2013;4:33-8.

5. Gray GC. The Ethics of Pharmaceutical Research Funding: A Social Organization Approach. J Law Med Ethics. 2013;41:629-34. Fall.

6. Altisent R. La ética del desarrollo profesional continuado en la promoción de la calidad asistencial. Acta Bioethica. 2010;16:155-64.

7. Martínez Bullé Goyri V. Bioética, derecho y derechos humanos En: Perspectivas de Bioética. México. Universidad Nacional Autónoma de México. Facultad de Filosofía y Letras. Comisión Nacional de los Derechos Humanos. FCE. 2008.

8. De la Garza MT. Bioética y Biopolítica Perspectivas de Bioética. México. Universidad Nacional Autónoma de México. Facultad de Filosofía y Letras. Comisión Nacional de los Derechos Humanos. FCE. 2008.

9. Gómez A, Latorre C, Carreño JN. Dilemas éticos en las relaciones entre la industria farmacéutica y los profesionales de la salud. Persona y Bioética. 2007;11:23-38.

10. Orlowski JP, Wateska L. The effects of pharmaceutical Firm enticements on physician prescribing patterns. There's no such thing as a free lunch. Chest. 1992;102:270-3.

11. Shaw B, Whitney P. Ethics and compliance in global pharmaceutical industry marketing and promotion: The role of the IFPMA and self-regulation. Pharmaceuticals Policy and Law. 2016;18:199-206, 10.3233/PPL-160443.

12. Niteesh K, Ch, Stelfox H, Th, Detsky AS. Relationships between authors of clinical practice guidelines and the pharmaceutical industry. JAMA. 2002;287:612-7.

13. Gracia D. Profesión médica, investigación y justicia sanitaria Colección Ética y Vida, 4. Bogotá: Editorial El Búho Ltda; 1998. 